14.3

\title{
Оценка жизнеспособности одиночных клеток и клеточных популяций in vitro с помощью импедансной спектроскопии во временном представлении
}

\author{
() Д.Д. Ступин ${ }^{1,2}$ \\ ${ }^{1}$ Санкт-Петербургский национальный исследовательский Академический университет РАН, \\ 194021 Санкт-Петербург, Россия \\ ${ }^{2}$ Университет ИТМО, \\ 197101 Санкт-Петербург, Россия \\ e-mail: Stu87@ya.ru, Stupin@spbau.ru
}

(Поступило в Редакцию 18 января 2018 г.)

Работа посвящена применению высокоскоростных методов электрической импедансной спектроскопии (ЭИС) - Фурье-ЭИС и ЭИС на основе адаптивной фильтрации (АФ-ЭИС) — для изучения клеточных популяций и одиночных клеток в физиологически естественных условиях in vitro. Сокращая продолжительность жизни клеток с помощью УФ облучения, показано, что гибель клеточной популяции позволяет зарегистрировать как Фурье-ЭИС, так и АФ-ЭИС, в то время как для оценки жизнеспособности одиночных клеток более надежный результат дает АФ-ЭИС. Последнее является следствием высокой помехоустойчивости АФ-ЭИС, которая в условиях внешнего зашумления, вызванного электромагнитными наводками, обеспечила возможность работы с безвредными для одиночных клеток 10-100 nA токовым откликом и $15 \mathrm{mV}$ зондирующим напряжением. Разработанная технология диагностики одиночных клеток может послужить фундаментом для создания прецизионных ток-синосенсоров и датчиков ионизирующего излучения, которые внесут существенный вклад в решение важнейших задач экологии и здравоохранения.

DOI: $10.21883 /$ JTF.2018.09.46432.28-18

\section{Введение}

Электрическая импедансная спектроскопия (ЭИС) $[1,2]$ является мощной экспериментальной методикой, которая используется для диагностики электронных приборов [3-5], в исследовании твердого тела и наноматериалов [6-9], при изучении электролитов [10-12], для характеризации альтернативных источников энергии [13-15] и во многих других областях науки и техники. В последнее время все большую популярность приобретают исследования, направленные на применение ЭИС для изучения „мягкой материи“ (soft matter), к которой относятся биологические объекты: органы, ткани, клетки, белки и т.д. [16-22]. ЭИС является неразрушающим, неоптическим, безметочным (labelfree) и чувствительным методом, который в то же время может работать в режиме реального времени $[1,2,23-26]$ и не требует сложного аппаратного обеспечения. Вышеперечисленные достоинства делают ЭИС крайне перспективной техникой для биомедицинских задач, в частности, для создания портативных биодатчиков [27].

Одно из первых практических применений ЭИС мягкой материи принадлежит Л.С. Термену, который в 1922 г. в Петрограде в ФТИ им. А.Ф. Иоффе создал бесконтактный музыкальный инструмент - „терменвокс“ $[28,29]$. Позднее лауреат Нобелевской премии по физике I. Giaever воплотил идею использования ЭИС для изучения клеточных популяций в технологии ECIS (Electrical cell-substrate impedance sensing, импедансное зондирование клеточной культуры), при- бор на основе которой выпускается компанией Applied Biophysics (США) [16]. ECIS представляет собой модернизированную чашку Петри, включающую два электрода размером $\sim 100 \mu \mathrm{m}$, на которые высаживается исследуемая клеточная культура и между которыми измеряется импедансный спектр (ИС). Согласно модели Giaever-Keese [19,30], при наличии клеток на электроде переменный электрический ток через него должен протекать не только через электрохимический импеданс $Z_{e / c}$, как в случае пустого электрода, но и через зазор между электродом и клеткой (рис. 1). Последнее приводит к появлению в импедансе $Z_{\mathrm{mec}}$ контакта металл/электролит/клетка (МЭК) дополнительного последовательного активного сопротивления зазора $R_{s}$, т. е.

$$
Z_{\mathrm{mec}}=Z_{e / c}+R_{s} .
$$

Таким образом, по временной эволюции $Z_{\mathrm{mec}}$ можно проводить диагностику состояния клеточной культуры, изучать подвижность клеток, определять степень покрытия электрода клетками и т.п. Технология ECIS нашла широкое применение в фармакологии [31], в области изучения опухолевых тканей $[32,33]$, процессов заживления ран [34] и т.д.

Идея использования ЭИС для изучения одиночных клеток была ранее выдвинута в работах $[18,35]$, в которых в отличие от технологии ECIS использовались микроэлектроды. Для измерения ИС авторы данных работ использовали помехоустойчивый метод синхронного усиления, который обеспечил работу с безопасными 


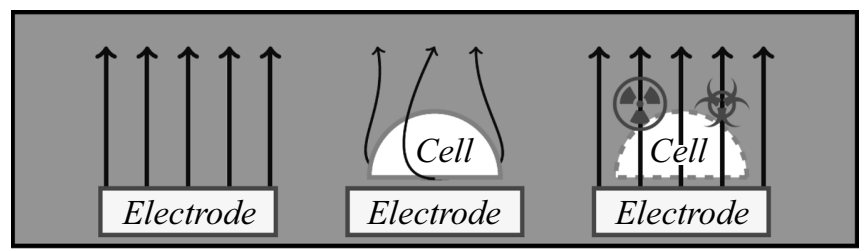

Рис. 1. Модель Giaver-Keese. Ток (стрелки) через контакт (МЭК) протекает не только через электро-химический импеданс $Z_{e / c}$, как в случае пустого электрода (левая панель), но также через зазор между поверхностью электрода и клеточной мембраной (центральная панель). Таким образом, импеданс контакта МЭК по абсолютной величине больше импеданса пустого электрода. В случае гибели клетки электрический ток может дополнительно протекать сквозь разрушенную клеточную мембрану в обход зазора, что приводит к уменьшению модуля импеданса контакта МЭК (правая панель). Данный феномен может быть использован для безметочной оценки жизнеспособности клеток.

для клеток низкими уровнями зондирующего напряжения $(\sim 10 \mathrm{mV})$ и токового отклика $(\sim 100 \mathrm{nA})$. Однако методика синхронного усиления обладает низкой скоростью измерений, и предложенная в $[18,35]$ технология ЭИС одиночных клеток может быть значительно улучшена, если для получения ИС использовать современные высокоскоростные методы ЭИС во временном представлении: Фурье-ЭИС [23,24] и ЭИС на основе адаптивной фильтрации [36] (АФ-ЭИС). Данные методы ЭИС сканируют образец одновременно в целой полосе частот, за счет чего достилается высокое частотное разрешение и высокая скорость измерений, что важно для исследования быстрых процессов, происходящих в клетках, например в момент их гибели. Также сокращение времени измерений позволит снизить влияние процесса измерения ИС на функционирование клеток.

Таким образом, целью настоящей работы является экспериментальная апробация ЭИС во временном представлении для исследования как одиночных клеток, так и клеточных популяций. При проведении данного исследования мы применили Фурье-ЭИС и АФ-ЭИС для детектирования наличия и отсутствия клеток на электроде, а также для оценки их жизнеспособности. В результате нами было установлено, что обе измерительные техники позволяют отличить живую клеточную популяцию от мертвой, в то время как более надежная оценка жизнеспособности одиночных клеток достигается с помощью АФ-ЭИС.

Настоящая работа построена следующим образом. В разд. 1.1 описывается экспериментальная установка для измерения ИС в режиме реального времени. Затем в разд. 1.2 приводятся протокол пробоподготовки клеток и дизайн проведения эксперимента. Завершается работа разд. 2 и 3, в которых приводятся и обсуждаются полученные результаты.

\section{1. Материалы и методы}

\section{1. Измерительная установка}

Для измерения ИС в настоящей работе использовалась экспериментальная установка, схема которой изображена на рис. 2. В качестве источника зондирующего напряжения $V_{k}$ использовался генератор АКИП-3413-3 (АКИП, Россия), включенный в режиме осциллятора с качающейся частотой (sweep-mode, развертка по частоте). Частотный диапазон зондирующего напряжения составлял от $10 \mathrm{~Hz}$ до $40 \mathrm{kHz}$, амплитуда зондирующего напряжения составляла $15 \mathrm{mV}$.

Для интерпретации результатов эксперимента с точки зрения линейной системы и для уменьшения воздействия на образец, очевидно, необходимо работать с малыми напряжениями $(<25 \mathrm{mV})$ и, как следствие, с малыми токами порядка 10-100 nA [35]. Для измерения столь низких значений токов в настоящей работе использовался трансимпедансный преобразователь ток-напряжение на базе операционного усилителя AD8606 (Analog Devices, CША). Для записи зондирующего напряжения $V_{k}$ и токового отклика $J_{k}$ использовался четырехканальный аналогово-цифровой преобразователь L-Card E20-10 (L-Card, Россия). Частота дискретизации составляла $500 \mathrm{kHz}$, на всех каналах было выставлено единичное усиление. Время сбора данных для одного измерения составляло $500 \mathrm{~ms}$.

Для обеспечения возможности работы как с одиночными клетками, так и с клеточной популяцией в данной работе использовалась коммерческая мультиэлектродная матрица 60StimMEA200/30-Ti (Multichannel Systems, Германия), представляющая собой чашку Петри с расположенным на дне планарным массивом из восьми прямоугольных электродов размером $50 \times 250 \mu \mathrm{m}^{2}$ (рис. $\left.3, a, b\right)$ и 68 электродов диаметром $30 \mu \mathrm{m}$ (рис. $4, a, b)$. Большие электроды использовались для исследования клеточных популяций, а маленькие электроды - для изучения одиночных клеток.

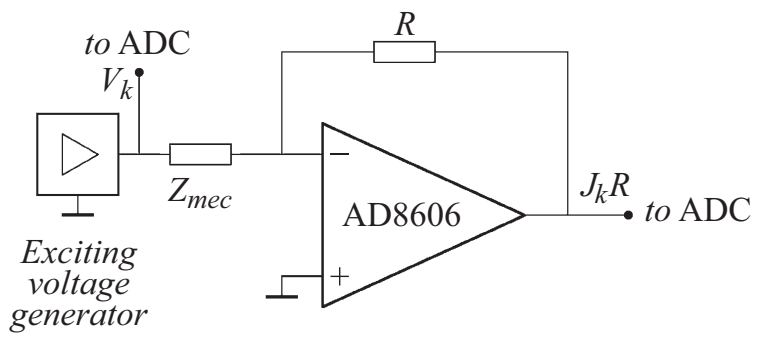

Рис. 2. Схема установки для измерения импедансного спектра. Операционный усилитель включен по схеме трансимпедансного преобразователя ток-напряжение и выполняет функцию амперметра. Здесь $R-1 \mathrm{M} \Omega$ - сопротивление обратной связи амперметра, $Z_{\mathrm{mec}}$ - импеданс контакта МЭК, $V_{k}$ и $J_{k}$ - временные последовательности зондирующего напряжения и токового отклика соответственно, ADC (analog-to-digital converter) - аналогово-цифровой преобразователь. 
$a$

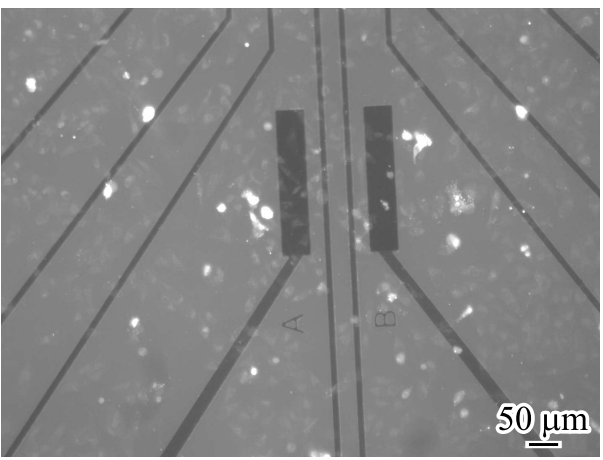

$c$

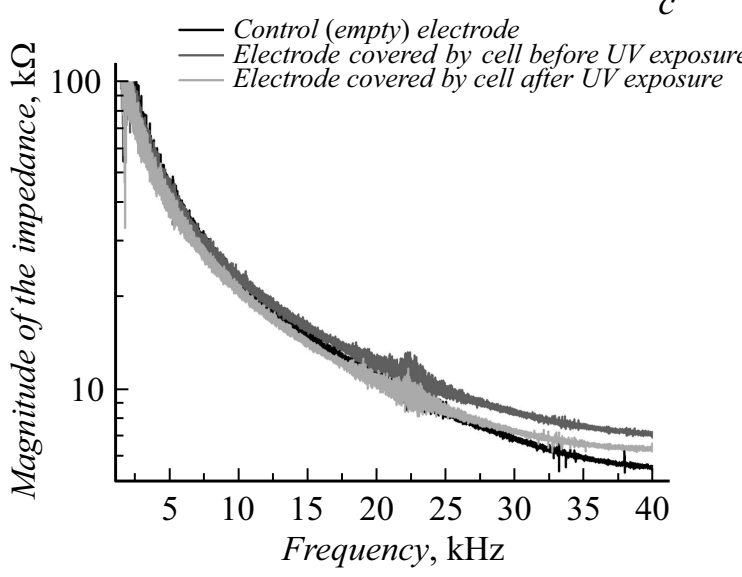

$e$

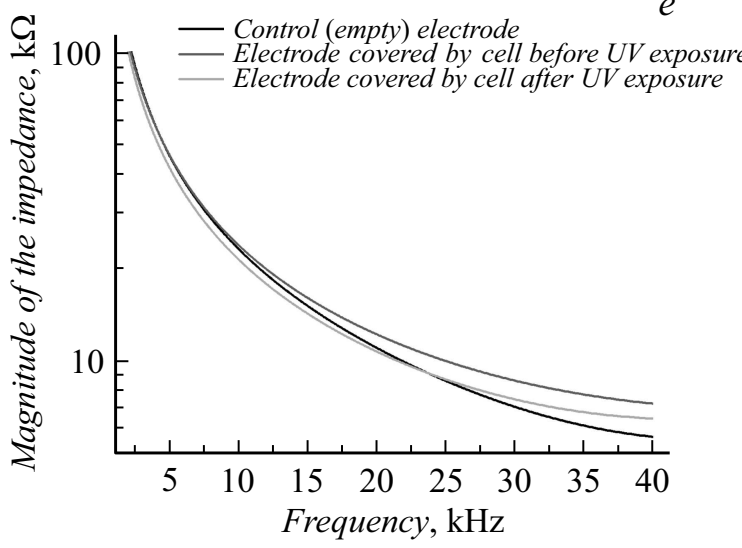

$b$

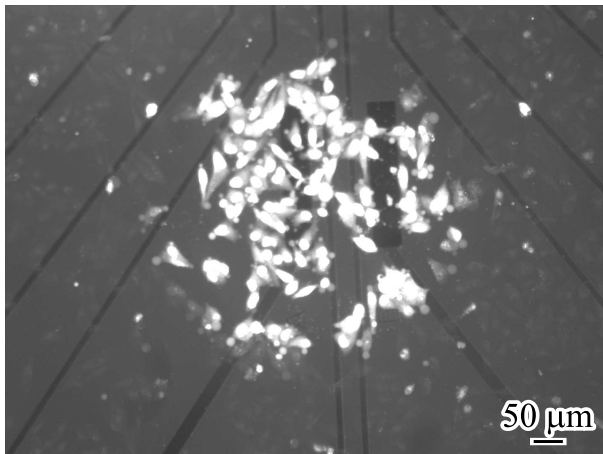

$d$

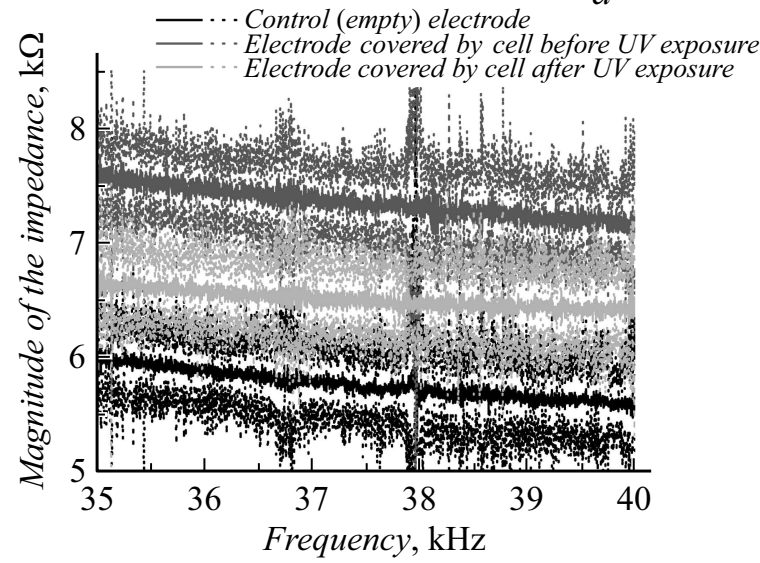

$f$

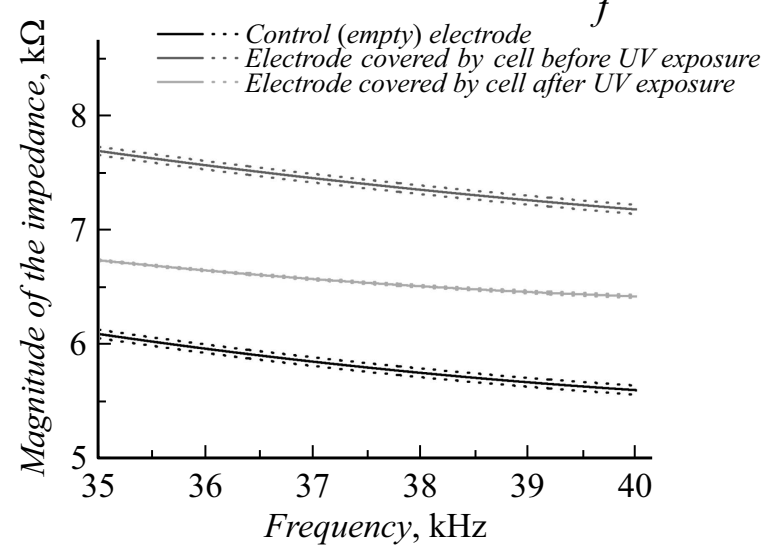

Рис. 3. Влияние УФ излучения на импедансный спектр электрода, покрытого клеточной популяцией: $a, b-$ фотографии электрода, покрытого клеточной популяцией, до и после УФ облучения соответственно (левый прямоугольный электрод); $c, d-$ полученные с помощью преобразования Фурье импедансные спектры и их высокочастотные составляющие части; $e, f$ - полученные с помощью адаптивной фильтрации импедансные спектры и их высокочастотные составляющие части. Черные кривые соответствуют пустому электроду (на фотографиях отсутствует), темно-серые - электроду, покрытому живыми клетками, светло-серые - электроду, покрытому мертвыми клетками. Среднее значение модуля импеданса обозначено сплошными линиями, а соответствующие погрешности - штриховыми. Видно, что гибель клеток сказывается на уменьшении модуля импеданса электрода, на котором они находятся. Однако в случае использования преобразования Фурье полученные данные имеют большую погрешность измерений, которая сравнима с вызванными гибелью клеток изменениями в импедансных спектрах, в то время как импедансные спектры, полученные с помощью адаптивной фильтрации, имеют пренебрежимо малую погрешность измерений, что значительно повышает надежность оценки жизнеспособности клеток.

Измерение импеданса проводилось следующим образом. Для каждого размера электрода измерялся импеданс между покрытым клетками (или клеткой) электро- дом (исследуемый электрод) и пустым прямоугольным электродом (референсный электрод). Параллельно в каждом эксперименте проводилось контрольное измере- 
$a$

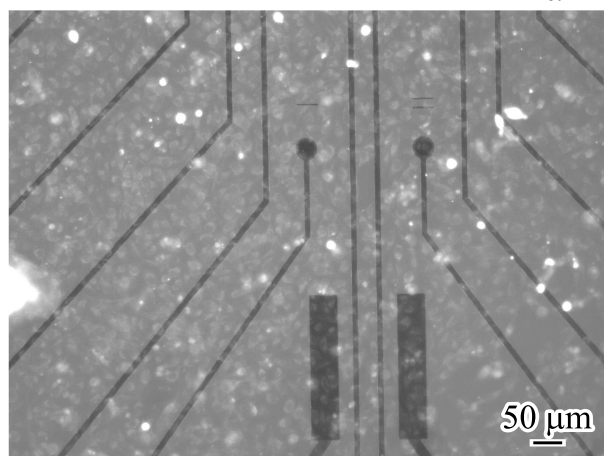

$c$

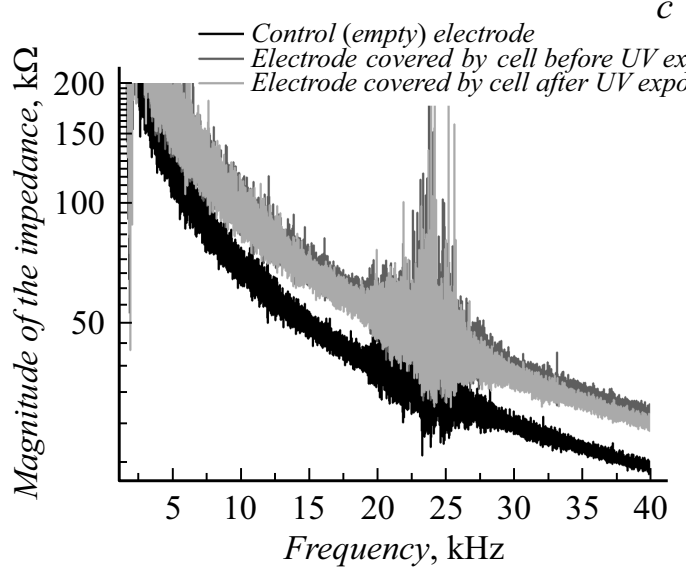

$e$

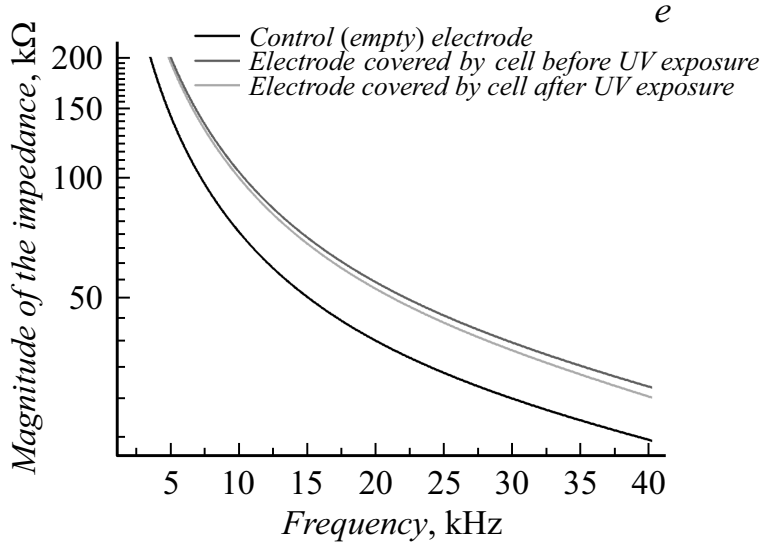

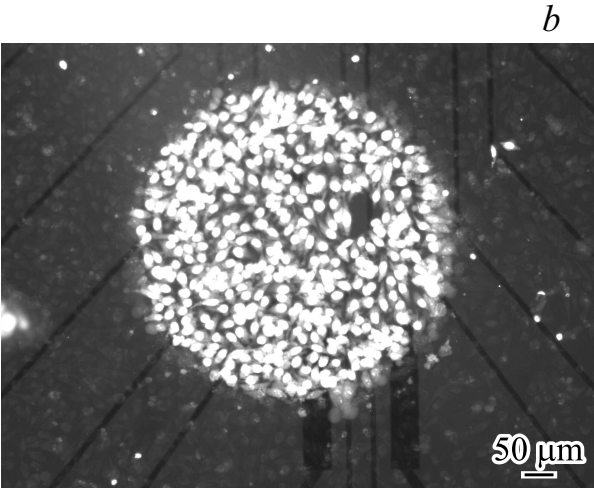

$d$

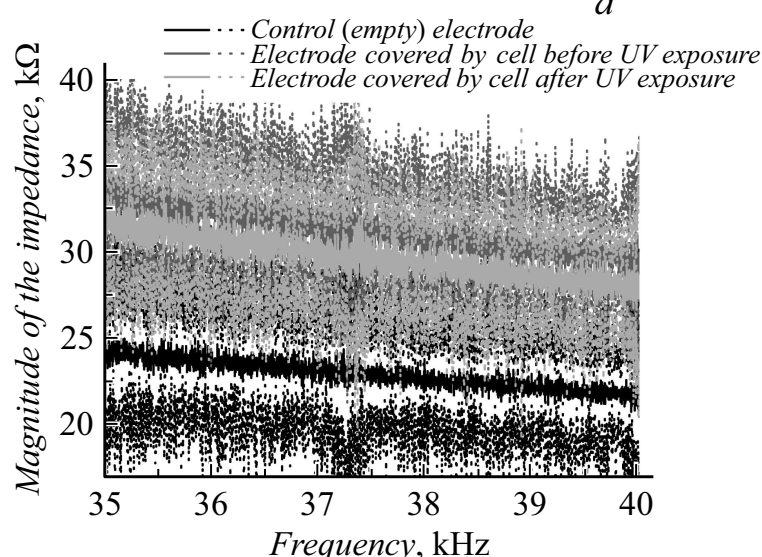

$f$

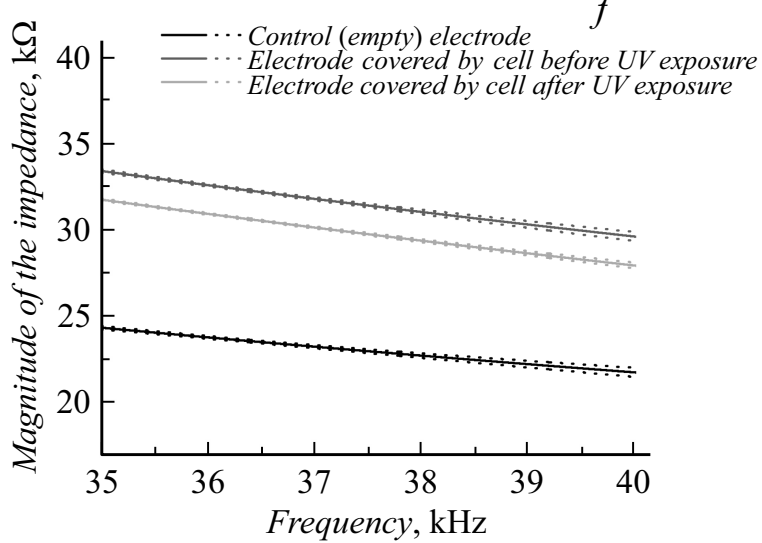

Рис. 4. Влияние УФ излучения на импедансный спектр электрода, покрытого одиночной клеткой: $a, b-$ фотографии электрода, покрытого одиночной клеткой, до и после УФ облучения соответственно (левый круглый электрод); $c, d-$ полученные с помощью преобразования Фурье импедансные спектры и их высокочастотные составляющие части; $e, f$ - полученные с помощью адаптивной фильтрации импедансные спектры и их высокочастотные составляющие части. Цветовые и стилевые обозначения кривых на спектрах аналогичны рис. 3. На полученных с помощью адаптивной фильтрации спектрах наблюдается согласующееся с моделью Giaever-Keese достоверное уменьшение модуля импеданса, которое вызвано гибелью клетки. В то же время в спектрах, полученных с помощью фурье-преобразования, все изменения находятся на уровне погрешностей измерений и не позволяют сделать однозначную оценку жизнеспособности клетки.

ние импеданса между референсным и пустым (контрольным) электродом, который имел такие же размеры, как и исследуемый электрод.

Импедансные спектры были получены из временных последовательностей тока $J_{k}$ и напряжения $V_{k}$ двумя независимыми способами: с помощью быстрого преобра- зования Фурье $[23,24]$ и с помощью адаптивной фильтрации [36]. Для накопления статистики измерения проводились по пять раз. Для построения 99.9\%-доверительных интервалов предполагалось нормальное распределение ошибок измерений. Обработка результатов измерений проводилась в пакете MatLab. 


\section{2. Биологическая часть}

В качестве объекта исследования была использована линия раковых клеток HeLa, полученная из банка клеточных культур Института цитологии РАН. Культивация производилась в среде DMEM (Биолот, Россия) с добавлением 10\%-й телячьей эмбриональной сыворотки (Бполот, Россия, ингибитор раствора Трипсин-Версена) и $40 \mu \mathrm{g} / \mathrm{ml}$ гентамицина (Sigma, США, антибиотик). Клетки инкубировались в $\mathrm{CO}_{2}$-инкубаторе при содержании $5 \% \mathrm{CO}_{2}$ и температуре $37^{\circ} \mathrm{C}$. Для проведения эксперимента клетки рассеивались на мультиэлектродную матрицу по $5 \cdot 10^{5}$ клеток за $24 \mathrm{~h}$ до эксперимента. Перед проведением эксперимента клеточная среда заменялась на фосфатно-солевой буфер (Биолот, Россия).

Микрофотографии покрытого клетками дна матрицы были получены на флуоресцентном микроскопе Leica 4000B (Leica, Германия), в котором в качестве источника освещения было использовано ультрафиолетовое (УФ) излучение от флуоресцентной лампы Leica EL6000 (Leica, Германия). Для стороннего визуального контроля жизнеспособности клеток использовался краситель иодистый пропидий [37].

Для сокращения времени жизни клеток проводилось их облучение с помощью сфокусированного УФ излучения от флуоресцентной лампы Leica EL6000. Длина волны излучения составляла $365 \mathrm{~nm}$, интенсивность $7.5 \mathrm{~mW}$, длительность экспозиции - $15 \mathrm{~min}$, диаметр пятна засветки - $400 \mu \mathrm{m}$.

\section{2. Результаты и обсуждение}

Результаты эксперимента приведены на рис. 3 и 4. На панелях $a$ и $b$ обоих рисунков изображены фотографии дна матрицы до и после облучения клеток УФ соответственно. На остальных панелях обоих рисунков изображены импедансные спектры контрольного электрода и электрода, покрытого клетками.

Как несложно видеть, из всех полученных спектров, в высокочастотной области импеданс электрода, содержащего клетки, больше по абсолютной величине импеданса пустого электрода, что согласуется с моделью Giaever-Keese. Емкостной характер низкочастотной составляющей части спектров объясняется образованием двойного электрического слоя на границе металл/электролит [23], который вместе с объемным сопротивлением электролита входит как $Z_{e / c}$ в модель (1). Данная зависимость может быть использована для диагностики контакта МЭК. В частности, в случае выхода из строя электрода, например при его выгорании, импеданс контакта МЭК перестанет носить емкостной характер, а в случае деградации диэлектрика матрицы модуль импеданса резко уменьшится во всем частотном диапазоне.

Яркое свечение на рис. 3, $b$ и $4, b$ вызвано флуоресценцией иодистого пропидия, который проник сквозь разрушенную УФ излучением мембрану в ядра мертвых клеток [37]. При этом на спектрах, изображенных на рис. $3, c-f$, наблюдается уменьшение модуля импеданса, покрытого клетками электрода. Данный эффект объясняется моделью Giaever-Keese (рис. 1) и может быть использован для оценки жизнеспособности клеточной популяции. Стоит отметить, что в случае использования Фурье-ЭИС изменения в спектрах на рис. $3, d$ сравнимы со статистической погрешностью измерений (штриховые линии), в то время как погрешность измерений для АФ-ЭИС (рис. 3, $f$ ) пренебрежимо мала по сравнению с уменьшением ИС покрытого клетками электрода.

Существенно иная ситуация наблюдается при исследовании одиночных клеток (рис. $4, c-f$ ). В данном случае изменения в спектрах, полученных с помощью ФурьеЭИС, находятся на уровне погрешностей измерений и не позволяют провести оценку жизнеспособности клетки. В то же время спектры, полученные с помощью АФ-ЭИС, по-прежнему обладают пренебрежимо малой статистической погрешностью измерений, что позволяет сделать однозначный вывод о падении импеданса, вызванного гибелью клеток. Данное различие в спектрах Фурье-ЭИС и АФ-ЭИС объясняется помехоустойчивостью последней: уменьшением площади электрода привело к уменьшению протекающего через него тока $J_{k}$ и, как следствие, к уменьшению соотношения сигнал/шум, что увеличило статистическую погрешность полученных с помощью Фурье-ЭИС спектров. В противоположность Фурье-ЭИС адаптивная фильтрация, являясь простейшим искусственным интеллектом, автоматически распознала во входных последовательностях $V_{k}$ и $J_{k}$ полезный сигнал и отделила его от шумов, уменьшив тем самым статистическую погрешность, что и позволило достоверно зарегистрировать гибель одиночной клетки по временной эволюции ИС. Интересно также отметить, что спектры, полученные с помощью Фурье-ЭИС, обладают большой гетероскедасичностью в отличие от спектров АФ-ЭИС, в которых погрешность измерений слабо зависит от частоты.

\section{3. Выводы и перспективы}

Таким образом, из приведенных в предыдущем разделе экспериментальных данных можно сделать вывод о том, что применение адаптивной фильтрации для обработки данных повышает надежность полученной с помощью ЭИС оценки жизнеспособности одиночных клеток и клеточных популяций in vitro. Сочетая в себе достоинства Фурье-ЭИС - широкий диапазон частот и высокую скорость измерений - АФ-ЭИС обеспечивает дополнительную помехоустойчивость измерений импеданса, что делает ее применение крайне перспективным в области создания портативных биосенсоров, чувствительным элементом которых будет являться одиночная клетка, например датчиков на токсины или ионизирующее излучение. Подобные биодатчики могут найти широкое применение для автоматического контроля 
качества воды, для обнаружения ядовитых веществ в продуктах питания, а также для создания недорогих персональных токсиносенсоров в ядерной и аэрокосмической промышленностях и предприятий, работающих с опасными веществами. Мы надеемся, что разработанная нами технология АФ-ЭИС одиночных клеток также откроет новую нишу в экологических исследованиях и позволит решить большинство актуальных проблем здравоохранения.

Автор выражает благодарность оргкомитету конференции „Физика - наукам о жизни 2017“، за проведение замечательного мероприятия, также Коняхину С.В., Верлову И.А., Князеву И.А., Корневу А.А. и Дубине М.В. за всестороннюю помощью и поддержку.

Работа была выполнена при поддержке Фонда „Сколково“ (Соглашение о предоставлении гранта российской образовательной и научной организации от 19.12.2017 № 7) и Сколковского института науки и технологий (Генеральное соглашение о научно-исследовательской деятельности № 3663-MRA от 25.12.2017).

\section{Список литературы}

[1] Barsoukov E. Impedance spectroscopy: Theory, Experiment, and Applications. J. Ross Macdonald. John Wiley \& Sons, 2005.

[2] Lvovich V.F. Impedance Spectroscopy: Applications to Electrochemical and Dielectric Phenomena. 1 edition. Wiley, 2012.

[3] Лебедев Д.В., Давыдов А.А. // ФТП. 2000. Т. 34. Вып. 1. C. 113.

[4] Горбачук Н.И., Шпаковский С.В., Wieck А., Поклонский Н.А. // ЖТФ. 2010. Т. 80. Вып. 10. С. 74-82.

[5] Yahia I.S., Fadel M., Sakr G.B. et al. // Acta Phys. Polonica A. 2011. Vol. 120. N 3. P. 563-566.

[6] Берман Л.С., Лебедев Л.С. Емкостная спектроскопия глубоких центров в полупроводниках. Л.: Наука, 1981.

[7] Yuanhua Lin, Lei Jiang, Rongjuan Zhao, Ce-Wen Nan // Phys. Rev. B. 2005. Vol. 72. N 1. P. 014103.

[8] Jacak P.L. Quantum Dots. NanoScience and Technology. Berlin Heidelberg: Springer-Verlag, 1998. P. 83-96.

[9] Gesheva K., Arvizu M.A., Bodurov G. et al. // J. Phys.: Conf. Ser. 2016. Vol. 764. P. 012010.

[10] Tsai Y.-T., Whitmore D.H. // Sol. St. Ionics. 1982. Vol. 7. N 2. P. 129-139.

[11] Lelidis I., Barbero G. // Phys. Lett. A. 2005. Vol. 343. N 6. P. 440-445.

[12] Barbero G., Lelidis I. // Phys. Rev. E. 2007. Vol. 76. N 5. P. 051501.

[13] Ying Ting Set, Birgersson E., Luther J. // Phys. Rev. Appl. 2016. Vol. 5. N 5. P. 054002.

[14] Rau U. Advanced Characterization Techniques for Thin Film Solar Cells. Wiley-VCH, 2011. P. 81-105.

[15] Wang S., Verbrugge M., Vu L. et al. // J. Electrochem. Society. 2013. Vol. 160. N 11. P. A1962-A1970.

[16] Wegener J., Keese C.R., Giaever I. // Experimental cell research. 2000. Vol. 259. N 1. P. 158-166.
[17] Grimnes S. Bioimpedance and bioelectricity basics. Academic Press, Elsevier Ltd, 2015.

[18] Dittami G.M., Ayliffe H.E., King C.S., Rabbitt R.D. // J. Microelectromechanical Systems. 2008. Vol. 17. N 4. P. 850 862.

[19] Giaever I., Keese C.R. // Nature. 1993. Vol. 366. N 6455. P. 591.

[20] McAdams E.T., Jossinet J. // Physiological Measurement. 1995. Vol. 16. N 3A. P. Al.

[21] Jin S.-A., Poudyal S., Marinero E.M. et al. // Electrochimica Acta. 2016. Vol. 194. P. 422-430.

[22] Alfinito E., Reggiani L. // Phys. Rev. E. 2010. Vol. 81. N 3. P. 032902.

[23] Chang B.-Y., Park S.-M. // Annual Rev. Analytical Chem. 2010. Vol. 3. P. 207-229.

[24] Popkirov G.S., Schindler R.N. // Review of scientific instruments. 1992. Vol. 63. N 11. P. 5366-5372.

[25] Leisner M., Carstensen J., Föll H. // J. Electroanalytical Chem. 2008. Vol. 615. N 2. P. 124-134.

[26] Денда В. Шум как источник информации. Мир, 1993.

[27] Banerjee P., Bhunia A.K. // Trends Biotechnology. 2009. Vol. 27. N 3. P. 179-188.

[28] Ржевкин С.Н. // УФН. 1948. Т. 34. Вып. 1. С. 1-12.

[29] Theremin L.S., Petrishev O. // Leonardo Music Journal. 1996. Vol. 6. N 1. P. 49-50.

[30] Wegener J., Keese C.R., Giaever I. // Experimental Cell Research. 2000. Vol. 259. N 1. P. 158-166.

[31] Tlili C., Reybier K., Géloën A. et al. // Analytical Chemistry. 2003. Vol. 75. N 14. P. 3340-3344.

[32] Mondal D., RoyChaudhuri C. // IEEE Transactions on Nanobioscience. 2013. Vol. 12. N 3. P. 239-246.

[33] Abdur Rub Abdur Rahman, Lo C.-M., Bhansali S. et al. // IEEE Transactions on Biomedical Engineering. 2009. Vol. 56. N 2. P. 485-492.

[34] Keese C.R., Wegener J., Walker S.R., Giaever I. // Proceedings of the National Academy of Sciences of the United States of America. 2004. Vol. 101. N 6. P. 1554-1559.

[35] Asphahani F., Wang K., Thein M. et al. // Physical Biology. 2011. Vol. 8. N 1. P. 015006.

[36] Stupin D.D., Koniakhin S.V., Verlov N.A., Dubina M.V. // Phys. Rev. Appl. 2017. Vol. 7. P. 054024.

[37] Kenneth H.J., James A.S. // J. Histochemistry \& Cytochemistry. 1985. Vol. 33. N 1. P. 77-79. 